\title{
A Study on Patients with Obsessive Compulsive Disorder from Urban, Semi-Rural and Rural Areas of West Bengal
}

\author{
Rima Das ${ }^{1}$, Souvik Raychaudhuri ${ }^{2}$
}

\section{ABSTRACT}

Obsessive-Compulsive disorder (OCD) is a disorder prevalent in population across the world including India. In the present study we investigated OCD patients from Urban, Semi- rural and rural population in the state of West Bengal, India. Patients were evaluated for severity of OCD using the Yale-Brown Obsessive Compulsive Scale (Y-BOCS) and Socio-Economic status using standard Indian scale. No positive correlation was found between the socio-economic status and severity of OCD.

Keywords: Obsessive Compulsive Disorder, Y-BOCS , Socio-Economic Status, Urban, Rural.

Obsessive compulsive disorder (OCD) is a neuropsychiatric anxiety disorder, which is considered as chronic, heterogeneous, and is characterized by the presence of either obsessions and or compulsions [1]. Although OCD was not viewed as relatively severe condition until about two decades ago, but it is now viewed as one of the most prevalent psychiatric disorder [2]. It is one of the most disabling medical disorders too. According to the international OCD foundation, (2011) OCD is a disorder of brain and behavior. OCD causes severe anxiety in those affected. OCD involves both obsession (recurrent, unwanted thoughts) and compulsions (repetitive behaviours) that takes lot of time and get in the way of important activities the person values. Repetitive behaviours such as hand washing, counting, checking or cleaning are often performed with the hope of preventing obsessive thoughts or making them go away. Performing these so called "rituals" however provides only temporary relief and not performing them markedly increases anxiety. Still other clinicians have described OCD to be a severe psychiatric illness, particularly in any developing country such as India [3,4], which follows a chronic course and partially respond to treatment. It simultaneously causes severe impairment to the patient and disapprovingly affects the family members.

\footnotetext{
${ }^{1}$ Research Scholar, Department of Psychology, University of Calcutta, Kolkata, India

${ }^{2}$ Associate Professor, Department of Psychology, University of Calcutta, Kolkata, India

*Responding Author

(C) 2016, R Das, S Raychaudhuri; licensee IJIP. This is an Open Access Research distributed under the terms of the Creative Commons Attribution License (http://creativecommons.org/licenses/by/2.0), which permits unrestricted use, distribution, and reproduction in any Medium, provided the original work is properly cited.
} 


\section{A Study on Patients with Obsessive Compulsive Disorder from Urban, Semi-Rural and Rural Areas of West Bengal}

In the world in 1990, OCD is expected to be the eleventh leading cause of non-fatal burden, accounting for $2.2 \%$ of total years lived with disability (YLD) approximately same as schizophrenia [5]. OCD was the fourth most widespread psychiatric disorder with a lifetime prevalence of $2.5 \%$ [5]. Those with OCD are less likely to be married, more likely to be unemployed and more likely to report impaired social and occupational functioning in comparison to the people with other anxiety disorder or unipolar mood disorders. [6 ]. In the global population, OCD has a life time rate of 2-3\%. [5,6]. In comparison to Europe And North America where the rate is $2.3 \%$, there is only one epidemiological study from India, which showed life time prevalence of $0.6 \%$ which is considerably lower. [5,7]. Perhaps more than any other anxiety disorders, OCD is characterized by chronic waxing and waning of symptoms. Different attributions of illness, health, disease, symptoms and treatment where made by people of diverse cultural backgrounds.[8]. On the basis of cultural background, educational level, health beliefs, attitudes and knowledge people tries to understand mental illness [9].

Though western studies are available on nature and severity of OCD, studies from India are sparse. Thus, the present study is intended to identify the clinical manifestations and severity of OCD among Indian population in the state of west Bengal.

\section{METHODS}

For the study, we considered referred OCD patients across population groups: Urban, Semi-rural and rural. Patients were chosen from outpatient services (OPD) of government hospitals by consultant psychiatrist after they satisfied the ICD10 criteria (WHO, 1992) for diagnosis of OCD. Patients were then selected by clinical interview using YBOCS scale.

Inclusion criteria involved : 1) subjects diagnosed as suffering from OCD by a consultant psychiatrist, visiting the Psychiatric OPD of local medical colleges and hospitals; ii) age range between 16-45 years for both genders; iii) naïve or uninitiated subjects i.e ones who are not acquainted with is kind of testing were chosen; iv) those willing to participate after being briefed about the purpose of the research.

The exclusion criteria involved: i) those who have history of any kind of psychiatric illness prior to onset of OCD; ii) those with psychiatric co-morbidity except depression; iii) those having any kind of physical illness iv) people with history of epilepsy ; v) those with history of head injury and vi) people with physical and mental disability; vii) individuals with history of substance dependence or abuse and viii) individuals with history of developmental disorders.

\section{Data collection}

The following forms were used for collecting data- 1) information schedule (patient information including case history), 2) general health questionnaire GHQ28 [10], 3) Yale Brown Obsessive Compulsive scale (YBOCS) [11].; and 4) Socio-economic scale [12]. 


\section{A Study on Patients with Obsessive Compulsive Disorder from Urban, Semi-Rural and Rural Areas of West Bengal}

The socioeconomic score (SES) is calculated based on the scale for assessment of socioeconomic status by SC Tiwari and A kumar [12] from Department of Geriatric Mental Health, King George Medical University, Lucknow India. We adapted this scale for the present study which involves OCD patients in three populations : Urban, Semirural and Rural in the state of West Bengal. Based on the SES score each population was classified into three broad socioeconomic classes: i) High: this includes Upper Class as in the SES sheet; ii) Middle: this includes Upper Middle Class and Middle Class as in SES sheet; and iii) Low: this includes Lower Middle Class and Lower Class as in SES sheet.

Further for ease of computation (calculation) the term Urban is considered to include population residing in A1 and A class cities combined. For SES classification the semirural population was considered equivalent of B-I and B-II class cities combined. All rural population was considered equivalent to C-class towns. The cut-off scores for deciding High, Middle and Low SES is described in the table 1.

\section{Table 1}

\begin{tabular}{|l|l|l|l|}
\hline & \multicolumn{3}{|l|}{ Population category } \\
\hline SES Class & Urban & Semi-Rural & Rural \\
\hline High & $>63$ & $\geq 59$ & $\geq 51$ \\
\hline Middle & $33-63$ & $\geq 31-58$ & $\geq 21-50$ \\
\hline Low & $<33$ & $<31$ & $<21$ \\
\hline
\end{tabular}

We used the Y-BOCS scale to assess obsessions and compulsions. The range of severity for patients were categorized as: subclinical (0-7), Mild (8-15), Moderate (16-23), Severe (24-31) and Extreme (32-40) [12]. The Y-BOCS scale is independent of the specific nature of symptoms like counting or checking or washing, but is based on aspects of the symptoms as revealed by the patient during interview such as duration or interference, degree of resistance, etc. The scale is divided into two subscales: Obsession and Compulsion. For each subscale, five aspects of pathology are rated using scales ranging from 0-4:i) time spent, ii) interference, iii) distress from obsessions and iv) resistance to obsessions and v) control over obsessions. YBOCS total score is obtained as a sum of scores from both the subscales.

\section{Statistical analyses}

Data was analyzed using EpiInfo software [13] which is widely used for statistical analyses of medical and epidemiological data.

\section{RESULTS}

A total of 201 patients diagnosed as OCD across three populations was considered in this study. The Urban population consisted of total 92 patients with a mean age of $34.2 \pm 8.7$ (SD) yrs . Of 


\section{A Study on Patients with Obsessive Compulsive Disorder from Urban, Semi-Rural and Rural Areas of West Bengal}

these 54 (58.7\%) were males and 38 (41.3\%) females. Except one all other patients of the Urban population were Hindu by religion. For the semirural population a total of 50 patients were considered with 24 (48\%) males and 26 (52\%) females. The mean age of the semirural population was found to be $34.7 \pm 8.6$ (SD) Yrs. The rural population comprised of 59 patients with 32 (54.2\%) males and 27 (45.8\%) females. The mean age for this population was $35.3 \pm 7.3$ (SD) yrs. All members belonged to Hindu religion. The details are summarized in Table 2.

The socioeconomic status (SES) for each of the populations namely Urban, Semirural and Rural was categorized into three classes: High, Middle and Low as described in the Methods. Of the 92 urban patients, only 1 (1\%) belonged to High SES whereas 72 (78.2\%) and 19 (20.6\%) belonged to Middle and Low SES. Of the 50 patients from Semirural areas $45(90 \%)$ and 5 (10 \%) belonged to Middle and Low SES, while none belonged to High. All 59 patients (100\%) from rural population belonged to Middle SES. The details are summarized in Table 2.

The severity of OCD for all patients in the study was assessed by using the YBOCS scale. The mean YBOCS score for the urban, Semirural, and Rural populations was found to be $26 \pm 5.9$ (SD), $26.2 \pm 6.4$ (SD) and $25.6 \pm 3.6$ (SD) respectively.

We made a comparative analyses of severity of OCD in the different population based on the YBOCS score (Table 3). Of 92 patients residing in urban areas 17 (18.5\%) were extreme, 41 (44.5\%) had severe, 30 (32.6\%) had moderate and 4 (4.3\% ) had mild OCD. Of the 50 patient of the semirural population, 5 (10\%) were categorized as extreme, 33 (66\%) severe, 9 (18\%) moderate and 1 (2\%) mild. There were 2 patients having YBOCS score 7 and were considered as borderline. Majority of the rural population 40 (67.7\%) were categorized as severe, considerable proportion as moderate 15 (25.4\%) and very few 3 (5\%) in extreme and only 1 in Mild category.

Comparison of OCD severity (YBOCS) between the different population was carried out and suitable statistical analyses performed. Results are described below:

\section{a) Rural, Semirural and Urban}

Statistics based on YBOCS score is summarized in Table 4. Bartlett's test for inequality of population variances is Chi-squared $=19.34$, degrees of freedom $=2$ and $\mathrm{P}$ value $=0.001$. Since variances were not found equal, Kruskal-Wallis test for comparison of three populations was conducted. This test is equivalent of ANOVA. The Kruskal-Wallis $\mathrm{H}=2.33$, degrees of freedom $=2$ and P-value $=0.312$. Since P-value $>5 \%$ (standard level of significance), we state that the mean YBOCS scores are similar in three populations (not significantly different).

\section{b) Rural and Semirural}

Comparison between rural and semirural populations based on YBOCS scores (Table 4) does not reveal any significant difference $(\mathrm{P}-\mathrm{value}=0.576$, $\mathrm{t}$-value $=-0.5609$, $\mathrm{T}-\mathrm{Test})$. 


\section{A Study on Patients with Obsessive Compulsive Disorder from Urban, Semi-Rural and Rural Areas of West Bengal}

\section{c) Rural and Urban}

No significant difference in the YBOCS scores between Rural and Urban population (Table 4) was observed $(\mathrm{T}$-value $=0.502, \mathrm{P}$-value $=0.616$, $\mathrm{T}$-test $)$.

\section{d) Semirural and Urban}

No significant difference in the YBOCS scores (Table 4) between Rural and Urban population was observed $(\mathrm{T}$-value $=-0.531, \mathrm{P}$-value $=0.592$, T-test $)$.

Then distributions of disease severity (YBOCS) category across socio-economic classes for the different populations are summarized below. In the urban population the largest number of patients belonged to Middle SES. 38\% of patients were categorized as severe, $23.9 \%$ as moderate, $13 \%$ as extreme and 3.3\% as Mild. Only 19 patients out of 92 belonged to Low SES with largest number in the moderate YBOCS category (table 5). For the semirural population, 90\% belonged to Middle SES and10\% belonged to Low SES. Largest number of patients (29) belonging to Middle SES were found to be in severe YBOCS category (Table 6). In the rural population $40(67.7 \%)$ were found to be in severe followed by $15(25.4 \%)$ in moderate YBOCS categories. All rural patients belonged to Middle SES (table 7).

\section{DISCUSSION}

In the present study, 201 OCD patients were considered across three populations: Urban, semirural and Rural. Majority of the patients from the rural and urban populations were males, whereas in the semirural population the proportion of male to females was almost equal. The trend that males had higher rate than women is consistent with epidemiological studies reported elsewhere [14-15]. Patients on and above the age of 16 were considered in the study.

Socio-demographic data recorded in the study revealed that majority of patients in the urban population belonged to Middle SES with about a quarter belonging to the Low SES. In the Semirural population, majority of individuals belonged to Middle SES with only one-tenth belonging to the Lower SES. In the rural population, all members belonged to the Middle SES. The present study covered samples consisting of homogeneous population irrespective of ethnicity. Hence, ethnic trends were not determined.

The severity of OCD was determined in terms of YBOCS scale. The comparison of YBOCS scores across three population groups: urban, semirural and rural, did not reveal statistically significant differences. On the basis of YBOCS scores patients were divided into 'YBOCS categories'. The distribution of patients into various YBOCS categories was analyzed. It was observed that in rural and semirural populations, majority of patients ( $>60 \%)$ belonged to 'severe' YBOCS category, whereas in urban population less than 50\% were found to be 'severe' cases. 'Moderates' formed the second largest category in all populations. Urban population accounted for the most 'extreme' cases followed by semi-rural and rural population groups. 


\section{A Study on Patients with Obsessive Compulsive Disorder from Urban, Semi-Rural and Rural Areas of West Bengal}

The distributions of disease severity (YBOCS category) across socio-economic classes in all three population groups were studied. The samples surveyed in the present study shows higher rates of OCD in Middle SES group in all three population groups: rural, semirural and urban. This is similar to trends found in a recent study from Warangal, India (2016) [16], but in contrast to findings from other countries $[17,18]$ with different socio-cultural and religious scenarios.

\section{CONCLUSION}

The present study involved 201 OCD patients across urban, semirural and rural populations from West Bengal state of India. We did not find statistically significant differences between Urban, Semirural and rural populations in terms of YBOCS score analyses. However, it was observed that in rural and semirural population groups, majority of patients belonged to 'severe' YBOCS category, whereas the urban population had the largest proportion of 'extreme' cases. From the data set available, no correlation was observed between socioeconomic status and OCD severity across populations.

The present study is based on samples recorded from hospital or health centers and provides distribution of OCD patients across different socioeconomic strata from urban, rural and semirural populations. However, this does not reveal the prevalence of OCD in the population of West Bengal. To understand the prevalence of OCD, more detailed and informative studies can be undertaken in future.

\section{REFERENCE}

1. American Psychiatric Association. Diagnostic and statistical manual of mental disorders, $4^{\text {th }}$ Edition, Text revision. Washington, DC: American Psychiatric Association. , 2000: 429-484.

2. Weissman, MM., Bland, RC., Canino, GJ., et al. (1994) The cross national epidemiology of obsessive compulsive disorder. J Clin Psychiatry, 55: (suppl) : 5-10.

3. Trivedi, JK., Gupta, PK. (2010) An overview of Indian research in anxiety disorders. Ind J Psychiatry, 52 (7): 210-218.

4. Khandelwal, A., Aggarwal, A., Garg, A., Jiloha, RC. (2009) Gender differences in phenomenology of patients with obsessive compulsive disorder. Delhi Psychiatry J, 12 (1): 8-17.

5. Karno, M., Goldin, JM., Sorenson, SB., et al. (1988) The epidemiology of obsessive compulsive disorder in five US communities. Arch Gen Psychiatry, 45: 1094-1099.

6. Torres, AR., Prince, MJ., Bebbington, PE., et al. (2006) Obsessive compulsive disorder: prevalence, co-morbidity, impact and help-seeking in the British National Psychiatric Co-morbidity survey of 2000. Am J Psychiatry, 163: 1978-1985. 
A Study on Patients with Obsessive Compulsive Disorder from Urban, Semi-Rural and Rural Areas of West Bengal

7. Degonda, M., Wyss, M., Angst, J., et al. (1993) The Zurish study XVIII. Obsessive compulsive disorder and syndromes in the general population. Eur Arch Psychiatry Clin Neurosci, 243: 16-22.

8. Vaughn, LM., Jacquez, F., Baker, RC., et al. (2009) Cultural health Atributions beliefs and practices. Effects on health care and medical education. The Open Medical Education Journal, 2: 64-74.

9. Ekanayake, S., Ahmad, F., McKenzie, K. (2012) Qualitative cross-sectional study of the perceived causes of depression in southasian origin women in Toronto. BMJ Open, 2: e000641.

10. Goldberg, DP., Hillier, VF. (1979) A scaled version of the General Health Questionnaire. Psychol Med., 9(1):139-45.

11. Goodman, WK., Price, LH., Rasmussen, SA., et al. (1989) The Yale-Brown ObsessiveCompulsive Scale. I. Development, Use, and Reliability. Arch. Gen. Psychiatry, 46, 1006-1011.

12. Tiwari, SC., Kumar, A. and Kumar, A. (2005) Development and standardization of a scale to measure socio-economic status in urban and rural communities in India. Ind $J$ Med Res., 122 : 309-314.

13. Epi Info. Division of Health Informatics \& Surveillance (DHIS), Center for Surveillance, Epidemiology \& Laboratory Services (CSELS), CDC Atlanta, US.

14. Fatemeh-Assarin, MD., HosseinBiqam, MA., AsqarAsqarmejad. (2006) An epidemiological study of obsessive compulsive disorder among high school students and its relationship with religious attitudes. Arch Iranian Med.; 9: 104-107.

15. Heyman, I., Fombonne, E., Simmons, H., et al. (2001) Prevalance of obsessive compulsive disorder in the Britiish Nationwide survey of child mental health. $\mathrm{Br} \mathrm{J}$ Psychiatry, 179: 324-329.

16. Revoori, SR., Peddi, SK., Alladi, M. (2016) An epidemiological study and severity assessment of obsessive compulsive disorder in Warangal region, India. EJPMR, 3(4): 205-210.

17. Moreso, NV., Hernandez/Martinez, C., Val, VA., et al. (2013) Sociodemographic and psychopathological risk factors in obsessive compulsive disorder: Epidemiologic study of school population. Int J Clin Health Psychology, 13: 118-126.

18. Hanna, GL., Piacentini, J., Dennis, P., et al. (2002) Obsessive compulsive disorder with and without Tics in a clinical sample of children and adolescents. Depress Anxiety, 16: 59-63. 
A Study on Patients with Obsessive Compulsive Disorder from Urban, Semi-Rural and Rural Areas of West Bengal

Table 2

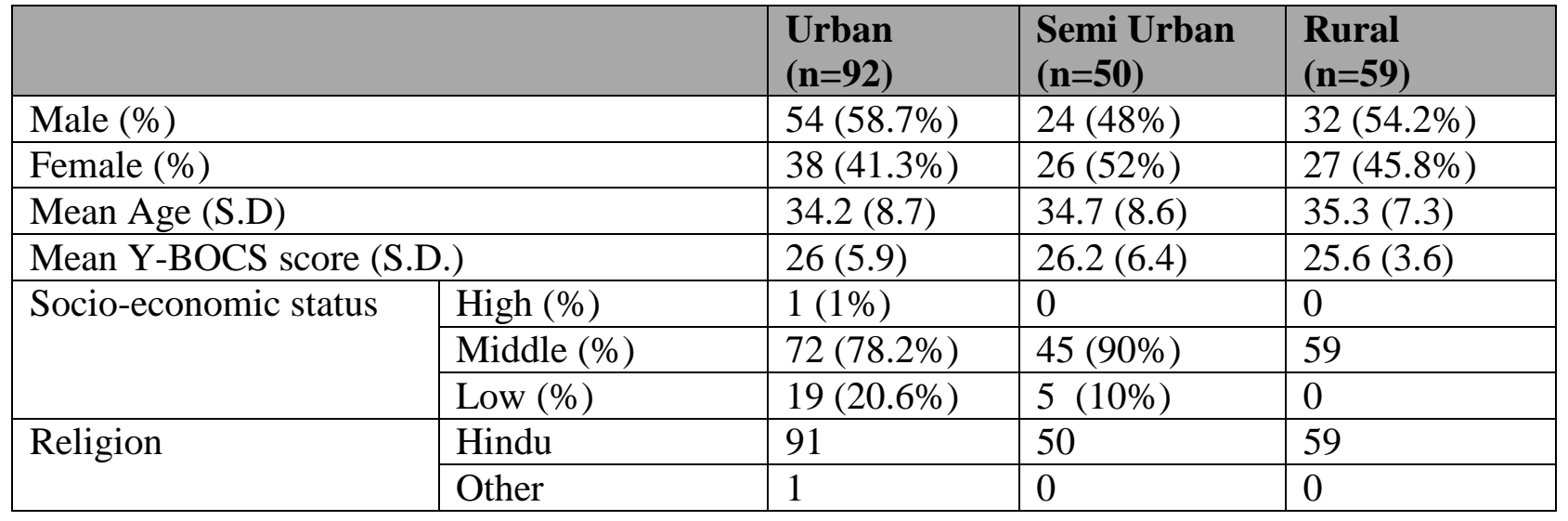

Y-BOCS Category (severity of disorder)

Table 3: population-wise distribution of Y-BOCS category

\begin{tabular}{|l|l|l|l|}
\hline Y-BOCS Category & $\begin{array}{l}\text { Urban } \\
(\mathbf{n = 9 2 )}\end{array}$ & $\begin{array}{l}\text { Semi Urban } \\
(\mathbf{n = 5 0 )}\end{array}$ & $\begin{array}{l}\text { Rural } \\
(\mathbf{n = 5 9 )}\end{array}$ \\
\hline Extreme & $17(18.5 \%)$ & $5(10 \%)$ & $3(5 \%)$ \\
\hline Severe & $41(44.5 \%)$ & $33(66 \%)$ & $40(67.7 \%)$ \\
\hline Moderate & $30(32.6 \%)$ & $9(18 \%)$ & $15(25.4 \%)$ \\
\hline Mild & $4(4.3 \%)$ & $1(2 \%)$ & $1(1.6 \%)$ \\
\hline Borderline/Subclinical & 0 & $2(4 \%)$ & 0 \\
\hline
\end{tabular}

Table 4: Comparison of Rural, Semirural and Urban population (Statistics on YBOC score)

\begin{tabular}{|c|c|c|c|c|}
\hline Population & $\begin{array}{c}\text { Number of } \\
\text { observations }\end{array}$ & Mean & SD & Median \\
\hline Rural & 59 & 25.6 & 3.6 & 26.0 \\
\hline Semirural & 50 & 26.2 & 6.4 & 27.0 \\
\hline Urban & 92 & 26.0 & 5.9 & 26.0 \\
\hline
\end{tabular}

Table 5: Severity of disease and SES status in Urban Population (n=92)

\begin{tabular}{|l|l|l|l|}
\hline \multirow{2}{*}{ Y-BOCS Category } & Socio-Economic status & Low \\
\cline { 2 - 4 } & High & Middle & 5 \\
\hline Extreme & 0 & $12(13 \%)$ & 5 \\
\hline Severe & 1 & $35(38 \%)$ & 8 \\
\hline Moderate & 0 & $22(23.9 \%)$ & 1 \\
\hline Mild & 0 & $3(3.3 \%)$ & 0 \\
\hline Borderline/Subclinical & 0 & 0 & \multicolumn{2}{l}{} \\
\hline
\end{tabular}

(C) The International Journal of Indian Psychology, ISSN 2348-5396 (e)| ISSN: 2349-3429 (p) | 93 
A Study on Patients with Obsessive Compulsive Disorder from Urban, Semi-Rural and Rural Areas of West Bengal

Table 6: Severity of disease and SES in Semi-Urban Population

\begin{tabular}{|l|l|l|l|}
\hline \multirow{2}{*}{ Y-BOCS Category } & \multicolumn{2}{|l|}{ Socio-Economic status } & Low \\
\cline { 2 - 4 } & High & Middle & 0 \\
\hline Extreme & 0 & 5 & 4 \\
\hline Severe & 0 & 29 & 1 \\
\hline Moderate & 0 & 8 & 0 \\
\hline Mild & 0 & 1 & 0 \\
\hline Borderline/Subclinical & 0 & 2 & \\
\hline
\end{tabular}

Table 7: Severity of disease and SES in Rural Population

\begin{tabular}{|l|l|l|l|}
\hline \multirow{2}{*}{ Y-BOCS Category } & \multicolumn{2}{|l|}{ Socio-Economic status } & Low \\
\cline { 2 - 4 } & High & Middle & 0 \\
\hline Extreme & 0 & 3 & 0 \\
\hline Severe & 0 & $40(67.7 \%)$ & 0 \\
\hline Moderate & 0 & $15(25.4 \%)$ & 0 \\
\hline Mild & 0 & 1 & 0 \\
\hline Borderline/Subclinical & 0 & 0 &
\end{tabular}

How to cite this article: R Das, S Raychaudhuri (2016), A Study on Patients with Obsessive Compulsive Disorder from Urban, Semi-Rural and Rural Areas of West Bengal, International Journal of Indian Psychology, Volume 3, Issue 4, No. 60, ISSN 2348-5396 (e), ISSN: 2349-3429 (p), DIP: 18.01.086/20160304, ISBN: 978-1-365-26308-8 